\title{
Plant competition as an ecosystem-based management tool for suppressing Parthenium
}

\section{hysterophorus in rangelands}

Fredrick Ojija ${ }^{\mathrm{a}, \mathrm{b}^{*}}$, Sarah E.J. Arnold ${ }^{\mathrm{a}, \mathrm{c}}$, and Anna C. Treydte $\mathrm{a}^{\mathrm{a}, \mathrm{d}}$

aDepartment of Sustainable Agriculture, Biodiversity and Ecosystem Management, School of Life Sciences and Bio-Engineering, The Nelson Mandela African Institution of Science and Technology, P.O. Box 447, Arusha, Tanzania.

bepartment of Applied Sciences, Mbeya University of Science and Technology, P.O. Box 131, Mbeya, Tanzania.

${ }^{c}$ Natural Resources Institute, University of Greenwich, Chatham Maritime ME4 4TB, UK

${ }^{\mathrm{d}}$ Hans Ruthenberg Institute, Agroecology in the Tropics and Subtropics, University of Hohenheim, Garbenstr. 13, 70599 Stuttgart, Germany

*Email: fojija@must.ac.tz

Key words: Competition experiment; Invasion; Rangeland management; Suppressive plants;

Tanzania

\section{Declarations of interest}

The authors declare there is no known competing financial interests or personal relationships that could have appeared to influence the work reported in this paper. This work is all original research carried out by the authors.

\section{Introduction}


Parthenium hysterophorus L. (Asteraceae) native to Mexico, Central and South America, is problematic invasive plant species in tropical and subtropical regions of Asia, Africa and Oceania. ${ }^{1}$ Similar to other invasive species, increased movement of people and goods, as well as transport across continents appears to have facilitated the spread of $P$. hysterophorus. ${ }^{2}$ Apart from causing biodiversity and agricultural loss, P. hysterophorus also reduces rangeland and grazing land quality, fodder quality, as well as quantity and productivity in invaded ecosystems. ${ }^{1,2}$ It alters vegetation structure towards monospecific stands (Parthenium-dominated communities) as it releases allelochemicals, which inhibit growth of neighbouring co-existing plants in the recipient ecosystems. ${ }^{3,4}$ Its Parthenin, which is toxic, makes $P$. hysterophorus non-palatable and responsible for the death of livestock and wildlife when consumed in large quantities (i.e. 10 to $50 \%$ of the diet) ${ }^{5}$ Some people also develop skin allergies and respiratory illness if repeatedly exposed to $P$. hysterophorus, especially flowers or pollen, which contain Parthenin. ${ }^{5}$ If $P$. hysterophorus is left uncontrolled, its invasion has the potential to impede the livelihood of local people, increase management costs associated with habitat restoration and herbicide application, ${ }^{6}$ and adversely affect biodiversity and ecosystem function. ${ }^{7}$

While many studies have investigated the harmful effects of $P$. hysterophorus on ecosystems, and its distribution in sub-Saharan Africa, ${ }^{4,7}$ little experimental work has been done to investigate sustainable and environmentally-friendly management approaches to control it. Even the control methods (i.e. bio-herbicides, synthetic herbicides, physical management, biological control and metabolites from fungal species) available in other countries have limited effects when used alone. ${ }^{5,8}$ There are also drawbacks, for instance, physical management, which involves hand-weeding or uprooting of $P$. hysterophorus is tedious, time consuming, and can affect human health. ${ }^{7}$ Manual removal techniques may further affect native flora and fauna communities through soil disturbance, which could 
disrupt soil dwelling organisms and roots or mycorrhizal systems of non-target species. ${ }^{9}$ Other management methods such as fire, grazing, shading or mowing might have unexpected consequences to the wider plant and animal community. ${ }^{9}$ Earlier studies reported that the most feasible way to reduce plant invasions in pastures or natural habitats is to maintain diverse assemblages of native or non-invasive forage plants. ${ }^{6,8,10,11}$ Moreover, increased plant species diversity and/or density in grasslands have suppressed invasive plants in some studies. ${ }^{6,10,12,13}$ For instance, the growth of the invasive weed, Ipomoea cairica $\mathrm{L}$., was suppressed when planted with competitive native plants (Pueraria lobata [Willd.] Ohwi or Paederia scandens [Lour.] Merr.). ${ }^{14}$ Hence, ecosystems or rangelands invaded by alien plants might be assisted in their recovery following invasive removal through the addition of competitive diverse forage species. ${ }^{6,8,9}$

Employing 'biocontrol plants' (i.e. plants introduced purposefully in ecosystems to enhance crop or habitat productivity, to manage pests, weeds or invasive plants) may also increase the efficiency of biological control agents and other management methods when they are integrated into the ecosystem. ${ }^{8,15}$ Biocontrol plants outcompete invasives for water, growth space, light, and impede their germination and growth. Hence, competitive forage species might be a potential management tool in Tanzania to control P. hysterophorus, particularly in natural habitats where herbicide application is not recommended. ${ }^{6,8,16}$ Though some forage plant species in Tanzania might be suitable biocontrol plants, they have not been studied for their suppressive ability against $P$. hysterophorus. Our primary objective was to test different plant species for their suppressive effect on $P$. hysterophorus growth. We hypothesized that higher numbers of competitive plant species negatively affect (i) growth parameters (i.e. stem height, diameter, root length, and biomass) and (ii) total leaf chlorophyll content of the invasive $P$. hysterophorus seedlings. We conducted field plot experiments to 
investigate the suppressive ability of legumes (Desmodium intortum L. [Fabaceae], Lablab purpureus L. [Fabaceae], and Medicago sativa L. [Fabaceae])) against P. hysterophorus.

\section{Materials and methods}

Characteristics of test plant species

Test plant species were selected based on their characteristics of being non-invasive, drought-resistant, a conservation cover crop species, and important fodder species for livestock due to their high protein content, high biomass production, and adaptability ${ }^{17}$. Additional competitive advantages of the test species over $P$. hysterophorus are their ability to fix atmospheric nitrogen. ${ }^{17-19}$ The test plant species are unlikely to become invasive because they have been grown for $>50$ years in east Africa to feed cattle and have not become problematic. ${ }^{17-19}$ Lablab purpureus (native to Africa) grows up to $6 \mathrm{~m}$ high in a diverse range of environmental conditions in bushland, grassland, and forest as it is highly adaptable. ${ }^{18,20,21}$ This species endures temperatures of $18-35^{\circ} \mathrm{C}$, and annual rainfall of $650-3000 \mathrm{~mm} \cdot{ }^{20}$ During the dry season, it remains green, making it an attractive fodder to livestock when other forages are scarce and dry. ${ }^{20}$ Desmodium intortum (native to South America) is an annual species, growing up to $7.5 \mathrm{~m}$ in height, in areas with annual rainfall of $900-3000$ $\mathrm{mm}$, and temperatures between 25 and $30^{\circ} \mathrm{C} .^{22,23}$ This species tolerates flooding, waterlogged habitats and shade. ${ }^{22,24}$ Medicago sativa, which is native to Asia, can live for several years at its ideal temperature range of $15-25^{\circ} \mathrm{C}$ and rainfall of $200-2500 \mathrm{~mm} \cdot{ }^{25-27}$ This species can reach up to $1 \mathrm{~m}$ high with numerous branches. ${ }^{25}$

\section{Competition experiments and seedling growth parameters}

In our experiments, we grew $P$. hysterophorus for 50 days with different biocontrol plant species compositions, and we assessed P. hysterophorus fitness using seedling height, 
stem diameter, root length, dry biomass, and total leaf chlorophyll content in Tanzania. We obtained P. hysterophorus seeds from the Agricultural Division at the Tropical Pesticide Research Institute (TPRI) in Tanzania. Desmodium intortum and M. sativa seeds were purchased from Kibo Seed Company Ltd. in Arusha, Tanzania. Lablab purpureus seeds were collected from the Department of Sustainable Agriculture, Biodiversity and Ecosystem Management at Nelson Mandela African Institution of Science and Technology (NM-AIST) in Arusha.

We investigated the suppressive effects of test plants $D$. intortum, $M$. sativa, and $L$. purpureus on $P$. hysterophorus seedling growth vigor in $1 \mathrm{~m}^{2}$ field plots at NM-AIST Tengeru campus $\left(3^{\circ} 24.149^{\prime} \mathrm{S}\right.$ and $36^{\circ} 47.790^{\prime} \mathrm{E}, 1197 \mathrm{~m}$ a.s.1). The mean annual temperature in Tengeru is $19.5^{\circ} \mathrm{C}$ and average annual rainfall is $1078 \mathrm{~mm} .{ }^{1}$ The area is characterised by black clay loam soil. ${ }^{1}$

Twenty-five seeds of $P$. hysterophorus and test plant species each were sown in 5 plots at varying combinations of mixtures with a monoculture as a control. Plant seedlings were grown at a density of 6 P. hysterophorus/10 test plants per plot (Table 1 ). The total of 11 planting combinations was replicated five times to make 55 planting plot trials (Table 1). Each plot was irrigated daily in the morning with 41 of water.

The 50-day-old seedlings of $P$. hysterophorus were harvested from each plot without destroying roots to assess the test plants' suppressive effects on invasive growth. The harvesting time was within the critical competition period of $P$. hysterophorus with various plants or crops. ${ }^{28,29}$ Growth metrics were stem height, stem diameter, root length, and aboveand below- ground dry biomass (ADB and BDB, respectively). Harvested seedlings were washed in water to remove dirt prior to separating into ADB and BDB components. Each component was placed in separate paper bags, dried in an $70^{\circ} \mathrm{C}$ oven for $72 \mathrm{~h}$. Root length, and stem height (from soil level to the tip of the tallest plant part) was measured using a 
meter ruler. Stem diameter (above the first two seedling leaves) and biomass were measured using digital callipers and an analytical balance, respectively. Additionally, an index of competition (i.e., relative interaction intensity [RII], (Equation 1)) was determined to assess performance of $P$. hysterophorus grown with suppressive species at different densities. ${ }^{30}$ If RII $<0$ competition prevails, $\mathrm{RII}>0$ facilitation prevails, and if $\mathrm{RII}=0$ the interaction is neutral or non-existent. ${ }^{30}$ RII ranges from 1 to $-1 .{ }^{30}$

$$
R I I=\left(B_{w}-B_{o}\right) \div\left(B_{w}+B_{o}\right)
$$

where, $\mathrm{B}_{0}$ and $\mathrm{B}_{\mathrm{w}}$ are $P$. hysterophorus biomass grown in monoculture and in mixture, respectively. We used the mean biomass over all replications for each planting combination.

\section{Measurement of leaf chlorophyll content}

Four young, fresh leaves from 10 P. hysterophorus individuals per plot were selected for analysis of total leaf chlorophyll content (i.e., total $\mathrm{Chl}) .{ }^{31}$ The total $\mathrm{Chl}$ was measured as an index of $P$. hysterophorus seedling health in response to suppressive effects of the competitive plant(s). We used $70 \mathrm{mg}$ of $P$. hysterophorus leaves immersed in $6 \mathrm{ml}$ of dimethyl sulfoxide (DMSO) in a test-tube, and incubated at $65^{\circ} \mathrm{C}$ for $12 \mathrm{~h} .{ }^{32,33}$ Afterwards, the extract was diluted to a total volume of $10 \mathrm{ml}$ with DMSO. We transferred $3 \mathrm{ml}$ of $P$. hysterophorus leaf chlorophyll extract onto a microplate to determine absorbance or optical density (OD) of the sample. The OD of the blank liquid (DMSO) and samples was determined under Synergy HTX Multi-Mode Microplate Reader (BioTek, U.S) at $663 \mathrm{~nm}$ and $645 \mathrm{~nm}$. Prior to calculating total Chl, the OD of the blank was deducted from the OD readings of every sample. We calculated total Chl using: ${ }^{32}$

$$
\text { Total Chl }=0.0202 A_{663}+0.00802 A_{645}
$$

Where, $A_{663}$ and $A_{645}$ are absorbance readings at $663 \mathrm{~nm}$ and $645 \mathrm{~nm}$, respectively.

Percentage change (PC) of $P$. hysterophorus growth parameter was calculated using: 


$$
P C=\left(G_{m}-G_{c}\right) \div G_{c}
$$

Where, $\mathrm{G}_{\mathrm{m}}$ and $\mathrm{G}_{\mathrm{c}}$ are $P$. hysterophorus growth parameters in mixture and control, respectively. A negative change was expressed as a decrease growth parameter value while a positive change was expressed as an increase in growth parameter value in planting mixture.

\section{Statistical analysis}

Stem height, stem diameter, root length, ADB, BDB, and total leaf Chl of $P$. hysterophorus were compared across suppressive species planting combinations using oneway ANOVA. ${ }^{1,31}$ We verified normality and homogeneity of variance using a Shapiro-Wilk test and Levene's test, respectively. ${ }^{31,34}$ The post-hoc Tukey-Kramer test (Tukey's honest significance test $)^{34}$ was used to separate the means at $p \leq 0.05$. We used the statistical software OriginPro 9.0 for data analysis ${ }^{34}$ at a significance level of $\alpha=0.05$.

\section{Results}

\section{Effect of suppressive plants on P. hysterophorus growth}

Overall, $P$. hysterophorus growth was more reduced when its seedlings were grown with L. purpureus in all combinations compared to other test plant species. P. hysterophorus seedlings had lower stem height, root length, shoot diameter, and biomass in mixtures than when grown in a monoculture. The stem height $\left(F_{(7,32)}=3.26, p=0.01\right)$, stem diameter $\left(F_{(7}\right.$, 32) $=1.67, p=0.0151)$, and root length $\left(F_{(7,32)}=11.77, p<0.0001\right)$ of $P$. hysterophorus seedlings grown with suppressive plants differed significantly between the number of suppressive plant species present (Fig. 1). Parthenium hysterophorus seedling stem height was $>40 \%$ shorter when grown with L. purpureus in all combinations, than when grown with $M$. sativa and/or D. intortum, or in a monoculture (Fig. 1). The root length of $P$. hysterophorus seedlings when grown with two or three suppressive species was $>54 \%$ 
shorter than when grown with one species or in a monoculture (Fig. 1). Also, it was $45 \%$ shorter when $P$. hysterophorus was grown with one suppressive species, in particular $L$. purpureus, compared to when grown alone or with either M. sativa or D. intortum. $P$. hysterophorus stem diameter was $>38 \%$ smaller when grown with two or three suppressive plant species than when grown in a monoculture or with one suppressive species (Fig 1).

Mean ADB and BDB of $P$. hysterophorus seedlings differed significantly between planting diversity and density $\left(\mathrm{ADB}: F_{(7,32)}=9.42, p<0.0001\right.$, and $\mathrm{BDB}: F_{(7,32)}=3.85, p=$ 0.0038, Fig. 2). Parthenium hysterophorus ADB was $>66 \%$ lower when grown with two (only in mixture of L. purpureus and D. intortum) or three suppressive species together than when grown in a monoculture or with one suppressive species. Also, when P. hysterophorus was grown with two or three suppressive species, BDB was $>50 \%$ lower than when grown either in a monoculture, with M. sativa or D. intortum (Fig. 2). The competition intensity of P. hysterophorus declined (lower values of RII) with increasing density of suppressive plant species (Table 2).

Effect of suppressive plants on P. hysterophorus leaf chlorophyll

Total Chl of $P$. hysterophorus differed significantly across suppressive plant species $\left(F_{(4,20)}=48.36, p<0.0001\right.$, Fig. 3). Suppressive species affected total Chl of $P$. hysterophorus negatively when grown with one (except $M$. sativa), two or three suppressive species. The total Chl of $P$. hysterophorus was reduced by $69 \%$ when grown with three suppressive plant species than when grown in a monoculture or in other combinations. Also, when P. hysterophorus was grown with two or one suppressive species (either D. intortum or L. purpureus), its total $\mathrm{Chl}$ was reduced by $>40 \%$ than when grown in a monoculture or with M. sativa only (Fig. 3). 


\section{Discussion}

We demonstrated that growth of $P$. hysterophorus seedlings was negatively impacted by suppressive forage species, particularly when the latter were combined. We found that $L$. purpureus was the primary species suppressing $P$. hysterophorus growth because all performance parameters were low across planting mixtures with L. purpureus. In contrast, in mixtures without this species, little or no significant suppressive effect was observed. For instance, in planting mixtures PMDL, PML, PDL, and PL, P. hysterophorus seedlings displayed lower biomass and reduced stem height. We showed that when the number of suppressive species in the plot was increased from one to two or three, $P$. hysterophorus stem height, biomass and total $\mathrm{Chl}$ decreased. This decrease followed a gradient of effectiveness (i.e., the gradient of most effective to least effective suppressive plant species: L. purpureus $>$ D. intortum $>M$. sativa) with little evidence that $M$. sativa alone could exert a suppressive effect. However, we advocate that the more and less suppressive species can be used together as rehabilitative species to complement each other in suppressing $P$. hysterophorus and improving livestock or wildlife forage availability as well as increasing ecosystem resilience against $P$. hysterophorus invasions.

The competition intensity index (RII) showed that suppressive plants at higher density negatively affected the total biomass of $P$. hysterophorus. Our findings are supported by previous research, which reported that resistance imposed by a single plant species to invasive species is weak compared to when several species are present. ${ }^{13,35,36}$ Our results suggest that high plant density in rangelands may reduce ecosystem invasibility, ${ }^{10}$ and highlights the importance of keeping rangelands from becoming impoverished or dominated by only a few grazing-tolerant species. ${ }^{37}$ Moreover, it also indicates competitive plant species seeded together with $P$. hysterophorus in communities of high species diversity may suppress invasion, which is in accordance with studies that found higher native or introduced 
plant diversity suppressed invasive plants in pastures. ${ }^{8,10,37,38}$ For instance, Khan et $\mathrm{al}^{38}$ reported that Setaria incrassata, Cenchrus ciliaris, Panicum maximum, and Eulalia aurea at higher abundance suppressed $P$. hysterophorus growth. Moreover, maintaining diverse forage plant communities may affect the amount of invasive species' seeds (or seed bank) in the soil. ${ }^{6}$ As $P$. hysterophorus seeds have a long dormancy, management methods such as high suppressive species diversity might help decrease the accumulation of invasive species seeds and avoid future potential invasions. Since ecosystem invasibility is influenced by habitat resource availability, ${ }^{6,39}$ increasing abundance and diversity of effective suppressive species may reduce ecosystem vulnerability to $P$. hysterophorus invasions as there is complete resource utilization. ${ }^{10,37}$ Therefore, management of $P$. hysterophorus using competitive suppressive plant species might promote long-term ecosystem resilience against invasions, and ensure ecosystem health and stability.

In our study, we observed a large area of ground cover of L. purpureus shading the rosette or juvenile plants of $P$. hysterophorus, which likely reduced their growth. This observation is similar to the findings of Tamado et $\mathrm{al}^{28}$ and Khan et al. ${ }^{38}$ Thus, we suggest management approaches to mitigate $P$. hysterophorus invasion using competitive forage species should target rosettes at an early growth stage. While $D$. intortum has been recommended for conservation of ground cover and pasture, ${ }^{22}$ we showed it can also be used to control P. hysterophorus. It is particularly effective when mixed with the most effective suppressive plant or grass species, such as L. purpureus, Digitaria eriantha, Urochloa mutica, and Pennisetum clandestinum, as it likely grows better in mixed stands. ${ }^{18}$ In addition to its extensive ground cover, L. purpureus also exhibits high stem height, root length, and biomass. We highlight that biological control through competitive plants is an approach with potential for managing $P$. hysterophorus in rangelands. It may benefit small land holders on a large scale by offering high yield without direct costs to growers while protecting the 
environment from $P$. hysterophorus. ${ }^{8,38}$ The use of non-native plant species is not advised for protected areas to control alien invasions, we used them because they are a financial benefit to pastoralists and agro-pastoralists. ${ }^{18-20,22}$

As $P$. hysterophorus causes allergic reactions in humans and animals in cases of skin contact during manual weeding or livestock handling,${ }^{40}$ our management approach would not require touching or uprooting it. Thus, our method could potentially reduce health risks to people, livestock, and wildlife. It is also a low-cost and sustainable management method for controlling this invasive species. Our selected suppressive species are readily available, drought tolerant, and can fix atmospheric nitrogen, which could possibly enhance their competitive fitness in mixtures over $P$. hysterophorus. ${ }^{19,20,41}$ Their non-target impacts on the environment are less severe compared to other biological control agents such as insects or microorganisms. ${ }^{15}$ However, we acknowledge that $P$. hysterophorus cannot be controlled by a single method per se, and thus, existing methods may be complemented with new management techniques. 5,8

\section{Conclusions}

We found that $P$. hysterophorus seedlings can be suppressed by forage species alone or in mixtures, primarily L. purpureus. To effectively control P. hysterophorus, seeding suppressive plant species must be included at an early invasion stage. For instance, before the emergence of rosettes and immediately following pulling of mature $P$. hysterophorus seedlings to create appropriate conditions (e.g. enough space, nutrients, water, and light) for quick establishment (e.g. increase in abundance and biomass) of suppressive species. We recommend that local communities be empowered with knowledge about suppressive potential of plant diversity and how to facilitate the planting of suppressive fodder species on their land. A coordinated national strategy and policy to mitigate invasive species is needed 
to ensure effective $P$. hysterophorus management in Tanzania. Furthermore, since our study is limited to germination and early growth stage of $P$. hysterophorus, future studies should test suppressive ability of forage species in already established invasive stands. While bioherbicides of alien plants could be considered for suppressing invasive species, ecologists should not plant them in protected areas to suppress $P$. hysterophorus as they may become deleterious or invasive in the ecosystem due to climate change and/or lack of their natural enemies. Accordingly, if ecologists or invasion biologists need to control the invasive species using non-native plants, they must first assess and quantify their impacts at various levels of ecological complexity.

\section{Acknowledgements}

The authors thank R. Kilewa from Agricultural Division at Tropical Pesticide Research Institute for providing $P$. hysterophorus seeds, P. Venkataramana in the Department of Sustainable Agriculture, Biodiversity and Ecosystem Management at the Nelson Mandela African Institution of Science and Technology (NM-AIST) for providing L. purpureus seeds, and the NM-AIST community for their support. We also thank all field assistants who supported the study. This study was funded by the World Bank through its African Centre of Excellence, “Centre for Research, Agricultural advancement, Teaching Excellence and Sustainability in Food and Nutritional Security (CREATES)", in the School of Life Sciences and Bioengineering at NM-AIST in Arusha, Tanzania. The Idea Wild supported us with research equipment.

\section{References}


1. OJIJA, F., S.E.J. ARNOLD, AND A.C. TREYDTE. 2019. Impacts of alien invasive Parthenium hysterophorus on flower visitation by insects to co-flowering plants. Arthropod-Plant Interactions 13:719-73. https://doi.org/10.1007/s11829-019-09701-3

2. AXMACHER, J.C., AND W. SANG. 2013. Plant invasions in China - challenges and chances. PLoS ONE 8: e64173. https://doi.org/10.1371/journal.pone.0064173.g001

3. FOXCROFT, L.C., W.D LOTTER, V.A. RUNYORO, AND P.M. MATTAY. 2006. A review of the importance of invasive alien plants in the Ngorongoro Conservation Area and Serengeti National Park. African Journal of Ecology 44:404-406. https://doi: $10.1111 / \mathrm{j} .1365-2028.2006 .00607 . \mathrm{x}$

4. WABUYELE, E., A. LUSWETI, J. BISIKWA, et al. 2015. A roadside survey of the invasive weed Parthenium hysterophorus (Asteraceae) in East Africa. Journal of East African Natural History 103:49-57. https://doi.org/10.2982/028.103.0105

5. KAUR, M., N.K. AGGARWAL, V. KUMAR, AND R. DHIMAN. 2014. Effects and management of Parthenium hysterophorus: A weed of global significance. International Scholarly Research Notices 1-12. http://dx.doi.org/10.1155/2014/368647

6. TRACY, B. F., I.J. RENNE, J. GERRISH, AND M.A. SANDERSON. 2004. Effects of plant diversity on invasion of weed species in experimental pasture communities. Basic and Applied Ecology 5:543-550. https://doi.org/10.1016/j.baae.2004.08.007

7. WITT, A., T. BEALE, AND B.W. VAN WILGEN. 2018. An assessment of the distribution and potential ecological impacts of invasive alien plant species in eastern Africa. Transactions of the Royal Society of South Africa 73:217-236. https://doi.org/10.1080/0035919X.2018.1529003

8. SHABBIR, A., K. DHILEEPAN, C. O’DONNELL, AND S.W. ADKINS. 2013. Complementing biological control with plant suppression: Implications for improved 
management of Parthenium weed (Parthenium hysterophorus L.). Biological Control 64:270-275. https://doi.org/10.1016/j.biocontrol.2012.11.014

9. FLORY, S.L., AND K. CLAY. 2009. Invasive plant removal method determines native plant community responses. Journal of Applied Ecology 46:434-442. https://doi.org/10.1111/j.1365-2664.2009.01610.x

10. KNOPS, J.M.H., D. TILMAN, N.M. HADDAD, et al. 1999. Effects of plant species richness on invasion dynamics, disease outbreaks, insect abundances and diversity. Ecology Letters 2:286-293. https://doi.org/10.1046/j.1461-0248.1999.00083.x

11. AMMONDT, S.A., AND C.M. LITTON. 2012. Competition between native Hawaiian plants and the invasive grass Megathyrsus maximus: Implications of functional diversity for ecological restoration. Restoration Ecology 20:638-646. https://doi.org/10.1111/j.1526-100X.2011.00806.x

12. VILÀ, M., J.L. ESPINAR, M. HEJDA, et al. 2011. Ecological impacts of invasive alien plants: a meta-analysis of their effects on species, communities and ecosystems. Ecology Letters 14:702-708. https://doi.org/10.1111/j.1461-0248.2011.01628.x

13. VILÀ, M., AND J. WEINER. 2004. Are invasive plant species better competitors than native plant species? - evidence from pair-wise experiments. Oikos 105:229-238. https://doi.org/10.1111/j.0030-1299.2004.12682.x

14. LI, W., J. LUO, X. TIAN, et al. 2015. A new strategy for controlling invasive weeds: Selecting valuable native plants to defeat them. Scientific Reports 5:1-11. https://doi.org/10.1038/srep11004

15. PAROLIN, P., C. BRESCH, C. PONCET, AND N. DESNEUX. 2014. Introducing the term 'Biocontrol Plants' for integrated pest management. Scientia Agricola 71:77-80. http://dx.doi.org/10.1590/S0103-90162014000100011 
16. NGONDYA, I.B., L.K. MUNISHI, A.C. TREYDTE, AND P.A. NDAKIDEMI. 2016. Demonstrative effects of crude extracts of Desmodium spp. to fight against the invasive weed species Tagetes minuta. Acta Ecologica Sinica 36:113-118. https://doi.org/10.1016/j.chnaes.2016.03.001

17. DEBELA, E., A. TOLERA, L.O. EIK, AND R. SALTE. 2012. Condensed tannins from Sesbania sesban and Desmodium intortum as a means of Haemonchus contortus control in goats. Tropical Animal Health and Production 44:1939-1944. https://doi.org/10.1007/s11250-012-0160-y

18. AGANGA, A.A., AND S.O. TSHWENYANE. 2003. Lucerne, Lablab and Leucaena leucocephala Forages: Production and utilization for livestock production. Pakistan Journal of Nutrition 2:46-53. https://doi.org/10.3923/pjn.2003.46.53

19. AMOLE, T.A., B. O. ODUGUWA, O. SHITTU, et al. 2013. Herbage yield and quality of Lablab purpureus during the late dry season in western Nigeria. Slovak Journal of Animal Science 46:22-30.

20. MADZONGA, Z., AND K. MOGOTSI. 2014. Production, harvest and conservation of Lablab purpureus (L) sweet forage in semi-arid livestock regions: the case of east central Botswana. Journal of Animal and Plant Sciences 24:1085-1090.

21. MAASS, B.L., M.R. KNOX, S.C. VENKATESHA, T.T. ANGESSA, S. RAMME, AND B.C. PENGELLY. 2010. Lablab purpureus - a crop lost for Africa? Tropical Plant Biology 3:123-135. https://doi.org/10.1007/s12042-010-9046-1

22. KARIUKI, J.N., G.K. GITAU, C.K. GACHUIRI, S. TAMMINGA, AND J.M.K. MUIA. 1999. Effect of supplementing napier grass with desmodium and lucerne on DM, CP and NDF intake and weight gains in dairy heifers. Livestock Production Science 60:81-88. https://doi.org/10.1016/S0301-6226(99)00035-4 
24. MAINA, J.M., M.W.K. MBURU, J.G. MUREITHI, et al 2006. Evaluation of legumes as cover crops for soil and weed management in smallholder coffee cropping systems in central Kenya. in Proc. 10th KARI Bien. Sci. Conf., 'Responding to demands and opportunities through innovative agricultural technologies, knowledge and approaches. https://www.feedipedia.org/node/18492

25. RADOVIC, J., D. SOKOLOVIC, AND J. MARKOVIC. 2009. Alfalfa-most important perennial forage legume in animal husbandry. Biotechnology in Animal Husbandry 25:465-475. https://doi.org/10.2298/BAH0906465R

26. AL-KAHTANI, S.N., E.K.A. TAHA, AND M. AL-ABDULSALAM. 2017. Alfalfa (Medicago sativa L.) seed yield in relation to phosphorus fertilization and honeybee pollination. Saudi Journal of Biological Sciences 24:1051-1055. https://doi.org/10.1016/j.sjbs.2016.12.009

27. LEI, Y., Y. XU, C. HETTENHAUSEN, et al 2018. Comparative analysis of alfalfa (Medicago sativa L.) leaf transcriptomes reveals genotype-specific salt tolerance mechanisms. BMC Plant Biology 18:1-14. https://doi.org/10.1186/s12870-018-1250-4

28. TAMADO, T., L. OHLANDER, AND P. MILBERG. 2002. Interference by the weed Parthenium hysterophorus L. with grain sorghum: Influence of weed density and duration of competition. International Journal of Pest Management 48:183-188. https://doi.org/10.1080/09670870110101739

29. SAFDAR, M. E., A. TANVEER, A. KHALIQ, R. AND MAQBOOL. 2016. Critical competition period of parthenium weed (Parthenium hysterophorus L.) in maize. Crop Protection 80:101-107. https://doi.org/10.1016/j.cropro.2015.11.002

30. ARMAS, C., R. ORDIALES, AND F.I. PUGNAIRE. 2004. Measuring plant interactions: A new comparative index. Ecology 85:2682-2686. https://doi.org/10.1890/03-0650 
31. OJIJA, F., S.E.J. ARNOLD, AND A.C. TREYDTE. 2019. Bio-herbicide potential of naturalised Desmodium uncinatum crude leaf extract against the invasive plant species Parthenium hysterophorus. Biological Invasions 21:3641-3653. https://doi.org/10.1007/s10530-019-02047-0

32. HISCOX, J.T., AND G.F. ISRAELSTAM. 1972. A method for the extraction of chlorophyll from leaf tissue without maceration. Canadian Journal of Botany 57:13321334. http://www.nrcresearchpress.com/doi/abs/10.1139/b79-163

33. NGONDYA, I.B., L.K. MUNISHI, A.C. TREYDTE, AND P.A. NDAKIDEMI. 2016. A nature-based approach for managing the invasive weed species Gutenbergia cordifolia for sustainable rangeland management. SpringerPlus 5:1-14. https://doi.org/10.1186/s40064-016-3480-y

34. ORIGIN(Pro). 2013. OriginLab Corporation, Northampton, MA, USA.

35. WEIGELT, A., AND P. JOLLIFFE. 2003. Indices of plant competition: Competition indices. Journal of Ecology 91:707-720. https://doi.org/10.1046/j.13652745.2003.00805.x

36. GRACE, J.B. 1995. On the measurement of plant competition intensity. Ecology 76:305308. https://doi.org/10.2307/1940651

37. CONNOLLY, J., M. SEBASTIÀ, L. KIRWAN, et al. 2018. Weed suppression greatly increased by plant diversity in intensively managed grasslands: A continental-scale experiment. Journal of Applied Ecology 55: 852-862. https://doi.org/10.1111/13652664.12991

38. KHAN, N., C. O’DONNELL, D. GEORGE, AND S.W. ADKINS. 2013. Suppressive ability of selected fodder plants on the growth of Parthenium hysterophorus. Weed Research 53:61-68. https://doi.org/10.1111/j.1365-3180.2012.00953.x 
39. PERKINS, L.B., E.A. LEGER, AND R.S. NOWAK. 2011. Invasion triangle: An organizational framework for species invasion. Ecology \& Evolution 1:610-625. https://doi.org/10.1002/ece3.47

40. O’DONNELL, C., AND S.W. ADKINS. 2005. Management of parthenium weed through competitive displacement with beneficial plants. Weed Biology \& Management 5:77-79. https://doi.org/10.1111/j.1445-6664.2005.00160.x

41. LATRACH, L., M. FARISSI, M. MOURADI, B. MAKOUDI, A. BOUIZGAREN, AND C. GHOULAM. 2014. Growth and nodulation of alfalfa-rhizobia symbiosis under salinity: electrolyte leakage, stomatal conductance, and chlorophyll fluorescence. Turkish Journal of Agriculture \& Forestry 38:320-326. https://doi.org/10.3906/tar-1305-52 
Table 1. Experimental design for planting plots with P. hysterophorus $(\mathrm{P})$ and suppressive plant species (S). P. hysterophorus (P) was grown in combination with Medicago sativa (M), Desmodium intortum (D) and Lablab purpureus (L). $\mathrm{S}_{0}=$ no suppressive plant species added, $\mathrm{S}_{1}=$ one species added, $\mathrm{S}_{2}=$ two species added, $\mathrm{S}_{3}=$ three species added. We used five replications per treatment.

\begin{tabular}{ccccc}
\hline \multicolumn{3}{c}{ Parthenium hysterophorus $(\mathbf{P})$ and suppressive } & Suppressive plant species grown \\
& \multicolumn{2}{c}{ plant species (S) } & alone & \\
\hline $\mathrm{PS}_{0}$ & $\mathrm{PS}_{1}$ & $\mathrm{PS}_{2}$ & $\mathrm{PS}_{3}$ & $10 \mathrm{M}$ \\
\hline $6 \mathrm{P}$ & $6 \mathrm{P} / 10 \mathrm{M}$ & $6 \mathrm{P} / 10 \mathrm{M} / 10 \mathrm{D}$ & $6 \mathrm{P} / 10 \mathrm{M} / 10 \mathrm{D} / 10 \mathrm{~L}$ & $10 \mathrm{~L}$ \\
& $6 \mathrm{P} / 10 \mathrm{D}$ & $6 \mathrm{P} / 10 \mathrm{M} / 10 \mathrm{~L}$ & $10 \mathrm{D}$ \\
& $6 \mathrm{P} / 10 \mathrm{~L}$ & $6 \mathrm{P} / 10 \mathrm{~L} / 10 \mathrm{D}$ & \\
\hline
\end{tabular}


Table 2. Relative interaction intensity (RII) for P. hysterophorus within each suppressive plant community combination. P. hysterophorus $(\mathrm{P})$ was grown in combination with Medicago sativa (M), Desmodium intortum (D) and Lablab purpureus (L).

\begin{tabular}{llllllll}
\hline Planting combination & PL & PD & PB & PLD & PLB & PBD & PLDB \\
& & & & & & & \\
\hline RII & -0.143 & -0.218 & -0.356 & -0.269 & -0.320 & -0.462 & -0.473 \\
& & & & & & & \\
\hline
\end{tabular}


Figure 1. Mean $( \pm \mathrm{SD})$ stem height $(\mathrm{cm})$, stem diameter $(\mathrm{mm})$, and root length $(\mathrm{cm})$ of $P$. hysterophorus seedlings when grown in a monoculture (light grey box), and with one (dark grey boxes), two (dashed boxes) or three (white box) suppressive plant species. Boxplots show the mean (square within boxes), $25 \%$ and $75 \%$ quartile ranges, and whiskers show standard deviations. Boxes with dissimilar letters are significantly different by TukeyKramer test at $p \leq 0.05 . \mathrm{P}=P$. hysterophorus, $\mathrm{M}=M$. sativa, $\mathrm{D}=D$. intortum, and $\mathrm{L}=L$. purpureus.

Figure 2. Mean $( \pm \mathrm{SD})$ above- and below- ground dry biomass $(\mathrm{g})$ of P. hysterophorus seedlings when grown in a monoculture (light grey box), and with one (dark grey boxes), two (dashed boxes) or three (white box) suppressive plant species. Boxplots show the mean (square within boxes), $25 \%$ and $75 \%$ quartile ranges, and whiskers show standard deviations. Boxes with dissimilar letters are significantly different by Tukey-Kramer test at $p \leq 0.05 . \mathrm{P}=$ P. hysterophorus, $\mathrm{M}=M$. sativa, $\mathrm{D}=D$. intortum, and $\mathrm{L}=L$. purpureus.

Figure 3. Mean $( \pm \mathrm{SD})$ index values of total leaf chlorophyll content of $P$. hysterophorus seedlings when grown in a monoculture (light grey box), and with one (dark grey boxes), two (dashed boxes) or three (white box) suppressive plant species. Boxplots show the mean (square within boxes), $25 \%$ and $75 \%$ quartile ranges, and whiskers show standard deviations. Boxes with dissimilar letters are significantly different by Tukey-Kramer test at $p \leq 0.05 . P=P$. hysterophorus, $\mathrm{M}=M$. sativa, $\mathrm{D}=D$. intortum, and $\mathrm{L}=L$. purpureus. 


\section{On the Ground Summary}

- The exotic invasive plant $P$. hysterophorus is invading rangelands in Africa while causing negative effects on the biodiversity, environment, economy, and human and animal health.

- There is a lack of effective eco-friendly control methods.

- We conducted experiments to investigate the suppressive effects of forage legume plant species Desmodium intortum (Fabaceae), Lablab purpureus (Fabaceae), and Medicago sativa (Fabaceae) in suppressing $P$. hysterophorus growth vigour

- Parthenium hysterophorus growth was suppressed when grown with fodder plant species at high density. But, the effect seemed to be mediated by the presence of $L$. purpureus

- Our work highlights the importance of keeping competitive native plants in rangelands.

- Moreover, this control method could be part of an integrated control toolkit deployed in a community-based approach in other countries. 